\title{
Classification of Disabilities Resulting from Leprosy, for Use in Control Projects*
}

\author{
Reprinted from Bull. Wld Hlth Org., 1969, 40, 609-612, by kind permission of
} Chief, Technical Publications, WHO

Among leprologists there has been an increasing interest in the prevention of disabilities as a part of each leprosy control project. This may be due in part to a recognition that, in addition to any direct benefit to the patient, the attention to disabilities has a favourable influence on attendance at treatment clinics and thus on the control of leprosy.

Both the International Leprosy Association in its congress reports and the WHO Expert Committee on Leprosy have emphasized the importance of including a programme of disability prevention in leprosy-control projects and to this end the WHO Expert Committee on Leprosy (see References) called for a simple and practical classification of disabilities which would be easy to understand and to apply under field conditions.

The WHO classification of disabilities which had been adopted by the WHO Expert Committee on Leprosy (see References) has been used by a number of groups in an attempt to assess the size and the nature of the problem. The WHO Leprosy Epidemiological Team (1960-67), for example, applied the classification in all its studies and collected a great deal of interesting data relating the development of disabilities to many variables in leprosy. The work of this team supported by other workers has made it possible to compare the frequency of different types of disability in various parts

*This memorandum was drawn up by P. W. Brand, Chief, Rehabilitation Branch, U.S. Public Health Service Hospital, Carville, La., U.S.A.; L. M. Bechelli, Chief, Leprosy, World Health Organization, Geneva, Switzerland; and V. Martinez Dominguez, Leprosy, World Health Organization, Geneva, Switzerland, after consultation with the leprologists whose names are shown in the acknowledgements at the end of this memorandum. of the world, and has given some idea of the magnitude of the problem and of the burden which leprosy disability places on the countries where leprosy is common.

It is from this background of existing surveys on a limited scale that WHO has set itself the task of preparing a simplified classification that may be more widely applied.

The medico-legal definition of a disability is "loss of function or earning power" and is graded only by the extent to which it interferes with a person's ability to earn his living or to enjoy a normal life. The WHO classification of disabilities mentioned above was not an attempt to identify the type of disability but was only a method of grading the severity of disability. Because it involved the summation of various types of disablement, the classification was not suitable for detailed record-keeping. For the same reason it was found to be rather complicated for use by those who were not trained to assess disabilities.

In preparing this new classification the following requirements were taken into account:

(1) To have a classification so simple and practical that it could be used by auxiliary health workers.

(2) To have a classification that would also be a guide to the auxiliary health worker and to the doctor with regard to the need for special preventive measures or treatment.

(3) To have a classification that would also be useful for collecting and classif ying information concerning disabilities in the field, so that data from different countries could be compared.

On the other hand, there are many factors that should be investigated and for which precise information on a world-wide basis is 
needed, but which would be difficult for an auxiliary medical worker to assess in the field. It is recognized that many workers will certainly use more detailed records both for research work and for follow-up of cases under treatment. Therefore, the proposed standard WHO field classification must emphasize simplicity and functional value with the hope that it will also be useful for comparisons of the frequency of disability in various parts of the world.

In the preparation of this proposed classification, the opinions of a large number of leprologists (listed at the end of this memorandum) were sought and their suggestions are gratefully acknowledged. The suggested new classification owes much to the scheme proposed by Dr. P. Laviron who has used a similar pattern in his work in Africa.

It is proposed to record separately the various factors that were summated together in the previous WHO classification, but to simplify the final grading system to 3 grades instead of 5 . This grading will apply only to hands, feet and eyes. Each grade is related both to severity of disability and also to the possibility of useful action, by the staff in the field. The grades are as follows:

(1) mild disability; warning of possible trouble in the future; need for education;

(2) moderate disability; therapeutic action needed to prevent severe disability;

(3) severe disability; may be too far advanced for effective treatment under field conditions.

The new classification is then as follows:

\section{Hand}

$1=$ Insensitive hand.*

$2=$ Ulcers and injuries and/or mobile claw hand and/or slight absorption.

$3=$ Wrist drop or fingers clawed and joints stiff and/or severe absorption* of fingers.

Foot

$l=$ Insensitive foot.*

$2=$ With trophic ulcer and $/$ or clawed toes or foot drop and/or slight absorption.

$3=$ Contracture and/or severe absorption.*

* See notes on insensitivity, absorption and stiffness.
Eyes

$1=$ Redness of conjunctiva.

$2=$ Lagophthalmos and/or blurring of vision and/or inflammation of globe.

$3=$ Severe loss of vision or blindness.

It will be noted that in each of the categories hands, feet and eyes, it is the grade 2 that is the most important for therapeutic action. This is the patient who most needs advice and attention or referral to the doctor or supervisor, and in each case there is some action that the field auxiliary can take. Each limb and each eye should be assessed separately and disabilities may be classified as in the following examples:

TABILE 1

\begin{tabular}{|c|c|c|}
\hline Hands & Feet & Eyes \\
\hline L R & L $\quad R$ & L $\quad \mathrm{R}$ \\
\hline 21 & $2 \quad 2$ & $\begin{array}{ll}1 & 3\end{array}$ \\
\hline
\end{tabular}

\section{USE OF CLASSIFICATION OR OF FORMS OR BOTH}

It is suggested that field auxiliaries should be provided with standard forms on which they can record details of each of their patients. The form, which should be part of the leprosy patient card, provides a simple and minimal record of the level of disability, by noting each of the factors that make for disability (see Table 2).

Alternatively, in those programmes in which it is felt that the task of entering details on such a form could not be carried out by the auxiliary, the grading may still be used without any record of the details of the disability. In such cases, absorption of the fingers will immediately be allocated to grade 3 without the need to consider either paralysis or insensitivity. It is hoped that by this simplification, every control project may at least begin to assess and record the frequency of disabilities, as a part of a programme of prevention. The use of record forms will provide better opportunities for observers to follow the progress of efforts to improve the situation.

Finally, it should be pointed out that the usefulness of the same basic form may be extended by those who have definitive pro- 
TABLE 2

Form for recording disabilities from leprosy

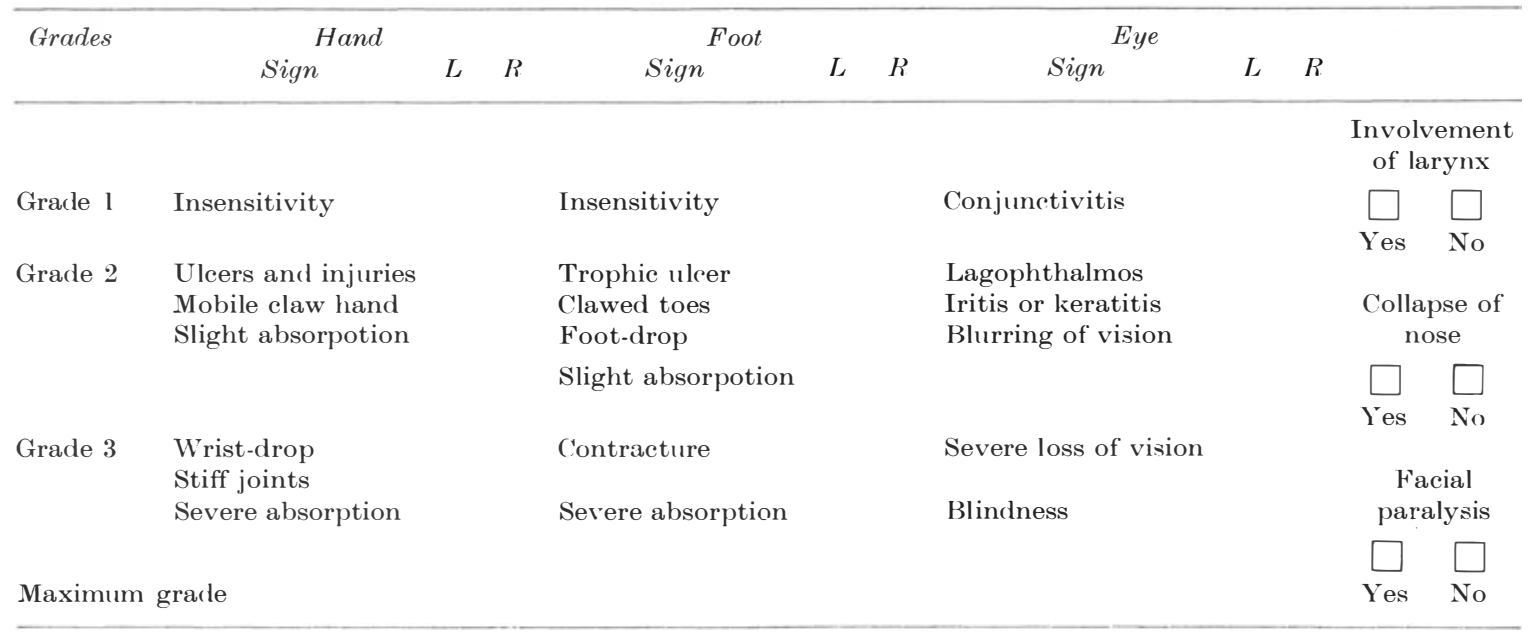

grammes for the study of disability. This may be done by keeping the same sequence of factors (insensitivity, paralysis, etc.) but making a finer anatomical subdivision of the hands and feet and recording separate digits, different parts of the foot and so on.

To use the form, each square in the section on hand, foot and eye should be marked if the disability is present, or left blank if it is absent. At the bottom of each column the grade (1, 2 or 3) should be noted, the most severe disability of that limb or eye being recorded.

In the last section, involvement of the larynx, collapse of the nose and facial paralysis, there is no grading, only a check-mark is entered for the presence of the disability.

It may seem strange to classify a hand as grade 3 if only one finger is absorbed. However, in this simplified system only a qualitative estimation is possible. For those who wish to collect more precise information, the same form may be used with the inclusion of additional vertical columns to subdivide, for example, each hand into ulnar and median parts or into individual digits.

\section{NOTE ON INSENSITIVITY}

The purpose of this assessment is to find out if the patient has lost protective sensation. The loss of light touch is not really a disability, but if a patient cannot localize a firm touch, he is liable to suffer frequent injury. Therefore, to test for insensitivity, the examiner may use the point of a pencil. The pressure should be firm enough to dimple the skin but not enough to move the patient's finger or hand; the patient's hand must be supported while it is tested. The blindfolded patient should point to the place where he believes he has been touched; pointing to the wrong place that may be as little as $2 \mathrm{~cm}$ from where he is touched is a sign of insensitivity. It has been shown that failure to localize firm touch is a useful sign that the patient is now in danger from mechanical injuries and burns.

\section{NOTE ON ULCERS AND INJURIES}

Haematomas, blisters and wounds are all signs of misuse of an insensitive hand. They indicate the need for education and the presence of any of them demands a grade 2 classification.

\section{NOTE ON ABSORPTION}

Absorption refers to a significant or manifest absorption. If only the tips of fingers are absorbed, a hand may still be classified as grade 2. In the foot, if as much as one-fifth of the sole area is lost this would be considered as grade 3 . 


\section{NOTE ON STIFFNESS}

The auxiliary worker should attempt to move the flexed fingers. If the fingers have a good range of passive movement, even though not quite $100 \%$, they may still be regarded as mobile but if they have $25 \%$ of their passive range they are classified as stiff.

\section{NOTE ON INFLAMMATION OF EYE}

The auxiliary worker should be taught to distinguish between the generalized redness of the conjunctiva in conjunctivitis and the circumcorneal redness indicating inflammation that involves the iris and the visual area of the eye. The latter is a grade 2 disability and demands urgent action. Photophobia or pain in the eye may also indicate iritis, while haziness or ulceration of the cornea should be marked as keratitis and also classified as a grade 2 disability.

\section{NOTE ON VISION}

It is recognized that the testing of vision is time-consuming under field conditions. However, commencing blurring of vision in lepromatous leprosy may be a vital sign of a reversible iritis.

It is suggested that the auxiliary worker should carry a card on which is drawn a split circle or $\mathrm{C}$ drawn to the dimensions of a letter on the $6 / 6$ row of Snellen's Test Type. The card may be about $10 \mathrm{~cm}$ by $10 \mathrm{~cm}$ and the split circle drawn in the centre. The circle is $9 \mathrm{~mm}$ in diameter, consisting of a black band $2 \mathrm{~mm}$ wide with a $2 \mathrm{~mm}$ gap on one side (see Fig. 1).

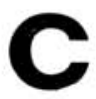

FIG. I

A normal eye can see the gap in the circle when the card is held at a distance of $6 \mathrm{~m}$. A medical auxiliary may hold the card 3 paces from the patient and ask him to point to the side of the circle in which there is a gap. Failure to see the gap at a distance of $3 \mathrm{~m}$ is recorded as blurring of vision. By turning the card in various ways, patients may be rapidly screened for poor vision in a very short time. Fach eye is covered while the other is tested.

In this grading, the eye may be recorded as "severe loss of vision, grade :3", if the patient cannot see the gap in the circle, even when the card is held directly in front of his face. The eye is recorded as blind if there is no perception of light.

\section{ACKNOWLEDGEMENTS}

The authors are grateful to the WHO Regional Offices and to the following leprologists who have replied to requests for opinions and suggestions on the new classification or who sent comments on the draft of the proposed classification. Dr. D. Beckett (Fiji), Dr. C. H. Binford (U.S.A.), Dr. M. Blanc (WH.O Regional Office for Africa), Dr. C. M. Brusco (Argentina), Dr. N. P. Buu-Hoi (France), Dr. J. Cap (WHO Regional Office for South-East Asia), Dr. F. Contreras (Spain), Dr. J. Convit (Venezuela), Dr. Dharmendra (India), Dr. J. C. Hargrave (Australia), I)r. O. W. Hasselblad (U.S.A.), Dr. C. G. S. Iyer (India), Dr. K. A. Kolesov (U.S.S.R.), Dr. C. B. Lara (Philippines), I)r. P. Laviron (France), Dr. J. Fraga Lima (Brazil), Dr. O. Manzi (Argentina), I)r. E. Muir (U.K.), Dr. F. Nousitou (WHO Regional Office for South-East Asia), Dr. T. Pompeu Rosas (WHO Regional Office for the Americas), Ir. E. W. Price (Ethiopia), Dr. J. N. Rodriquez (Philippines), Dr. A. Rotberg (Brazil), Dr. K. Saikawap (WHO Regional Office for the Western Pacific), Dr. A. Salazar Leite (Portugal), Dr. R. Sansarricq (Upper Volta), I)r. F. D. Schofield (Ethiopia), Dr. G. Tarabini (Somalia), Dr. J. Walter (WHO Regional Office for SouthEast Asia) and 1)r. R. Wardekar (India).

\section{REFERENCES}

WHO Expert Committee on Leprosy (196()). Wld Hlth Org. Rep. Ser. 319.

WHO Expert Committee on Leprosy (196()). Wld Hlth (Org. Techn. Rep. Ser. 319. 